\title{
Research and test on anti-corrosion and anti-scaling technology of downhole injection tools of Dagang Southern Oil Field
}

\author{
Hu Nan ${ }^{1}$ Yang Haichao ${ }^{1}$ Wei Haitao ${ }^{1}$ Li Wenjuan ${ }^{1}$ \\ 1.Dagang Oilfield Branch of China National Petroleum Corporation
}

\begin{abstract}
Every year, water well inspection operations accounted for $27.3 \%$ of the total water well operations due to corrosion and scaling of downhole injection tools in the Dagang Southern Oil Field, which seriously affects the validity period of the injection string and the effect of the injection, greatly increasing the production cost. Therefore, through the research and experiment of anti-corrosion and anti-scaling technologies such as $00 \mathrm{Cr} 25 \mathrm{Ni7Mo} 3 \mathrm{~N}$ dual-phase steel material, TiN coating, Ni-W-P coating and Ni-W-P-nSiO2 composite coating, a new type of anti-corrosion and anti-scaling technology for downhole injectiong tools has been developed. The field test results show that under the premise of ensuring the mechanical performance of the tools, the average corrosion rate of the supporting tools using the new anti-corrosion and anti-scaling technology is $0.0048 \mathrm{~mm} / \mathrm{a}$, which is far lower than the industry standard $0.076 \mathrm{~mm} / \mathrm{a}$. The successful test of this technology is of great significance to increase the effective period of the southern oilfield split injection and reduce production costs.
\end{abstract}

\section{Introduction}

Dagang Southern Oilfield complies with the requirements of China National Petroleum Corporation's water injection management regulations, since 2010, it has been forbidden to use tubing and Casing split injection, and the bridge-type concentric water distribution well split injection technology has been tested and applied. With the continuous expansion of the test scale, the application level of the split injection technology has been continuously improved. But it also brings some new problems, among them, due to the large number, complex structure, and high functional requirements of the downhole injection tools, they are greatly affected by the corrosion and scaling. During the test, there is less research on the anti-corrosion and anti-scaling technology of the matching tools, resulting in the average annual corrosion Scaling caused water well anew operations to account for $27.3 \%$ of the total water well operations, which seriously affected the application effect of split injection. At present, domestic scholars mainly research on surface water injection system and tubing anti-corrosion and anti-scaling technology, but less research on anti- corrosion and anti-scaling technology of downhole injection tools. Therefore, it is of great significance to carry out the research and test of anti-corrosion and anti-scaling technology for the downhole injection tools for improving the overall downhole injectiong tools application level in Dagang Southern Oilfield.

\section{Research and experimental method of anti-corrosion and anti-scaling technology for downhole injection tools}

At present, there are two main anti-corrosion treatment methods for tools at home and abroad. One is the preferred anti-corrosion material, such as various alloy steels, stainless steel, etc., which are mainly used for long-term active parts; the other is surface treatment technology, such as electroplating, chemical Plating, thermal spraying anticorrosive materials, etc., mainly used for long-term fixed parts. For the research on anti-corrosion and anti-scaling technology of downhole injection tools, it is necessary to take into account that the mechanical functions of the tools are not affected, and the stability and reliability are high, while meeting the economic adaptability of large-scale applications.

We divide the main structure of the downhole injection tools into two parts: one part is the part responsible for the main function of the tool, called the "moving body", and the other part mainly plays the role of fixing and protection, called the "fixed part". For the "moving body" part, it needs to be responsible for the mechanical function of the tool, mainly from the optimization of materials and economic evaluation; for the "fixed part" part, it mainly plays a role of protection and fixation, mainly from the optimization of anti-corrosion technology, economic evaluation. 


\subsection{Research on anti-corrosion and anti-scaling technology of "active subject"}

The material selection of the "active body" must meet the main mechanical functions of the tool, and have certain requirements for hardness, tensile strength, fatigue resistance, acid, alkali, salt corrosion, and processing and welding. Conduct investigations on scale alloy steel and stainless steel, and carry out experimental simulations based on field application conditions to determine the anti-corrosion and anti-scaling performance of various materials.

\subsubsection{Material selection}

Mainly investigate the mechanical properties and anti-corrosion and anti-scaling performance of alloy steel or stainless steel commonly used at home and abroad. Six materials of 45\#, 42CrMo, 2Cr13, 17-4PH, N80, $00 \mathrm{Cr} 25 \mathrm{Ni} 7 \mathrm{Mo} 3 \mathrm{~N}$ are initially selected for experimental testing.

\subsubsection{Anti-corrosion and anti-scaling test}

The indoor simulation of the downhole water injection environment $\left(90{ }^{\circ} \mathrm{C}, 150{ }^{\circ} \mathrm{C}, 25 \mathrm{MPa}, 35 \mathrm{MPa}\right)$ in the southern oilfield respectively. The simulated water was taken from the well water sample of the same well in the southern oilfield, and the simulated water was added with corrosive gas $(\mathrm{CO} 2: 100 \mathrm{mg} / \mathrm{L}), \mathrm{H} 2 \mathrm{~S}$ : $10 \mathrm{ppm})$ and no corrosive gas, the preliminary screening of the materials in two kinds of simulated water for anti-corrosion and anti-scaling detection and analysis under different temperature and pressure conditions, The examination time of each group was 21 days. a total of 108 sets of detection experiments, and according to JB/T7901-2001 Standard corrosion rate calculation.

\subsubsection{Mechanical function test}

According to the functional requirements of different downhole injectiong tools. Screening of mechanical properties of materials.

\subsubsection{Economic Evaluation}

Analyzing the price of materials required for the "active body" part of the main downhole injection tools, comprehensively consider the material performance and production and processing costs, and select the best material.

\subsection{Research on anti-corrosion and anti-scaling technology of "fixed parts"}

"Fixed parts" mainly play the role of connecting tubing and protecting and supporting the "moving body". There is basically no large displacement or deformation during the application process. The performance requirements are lower than that of the "moving body". Generally, it is more economical to use Surface treatment method for anti-corrosion and anti-scaling.

\subsubsection{Screening of surface anti-corrosion and anti-scaling treatment technology}

After comprehensively considering factors such as substrate performance, coating bonding ability, high temperature and high pressure resistance, safety and environmental protection, economy and other factors, Five surface treatment technologies such as Ni-W-P plating, Ni-P plating and Ti-N are adopted to conduct surface anti-corrosion and anti-scaling treatment on alloy steel substrates.

\subsubsection{Anti-corrosion and anti-scaling test}

The indoor simulated downhole water injection environment $\left(90^{\circ} \mathrm{C}, 150{ }^{\circ} \mathrm{C}, 25 \mathrm{MPa}, 35 \mathrm{MPa}\right)$ in the southern oilfield respectively. The simulated water was taken from the well water sample of the same well in the southern oilfield, and corrosive gas (including H2S: $10 \mathrm{ppm}$ ) was added to the simulated water. After anti-corrosion treatment, the substrate is put into simulated water for anti-corrosion and anti-scaling detection analysis under different temperature and pressure conditions. A total of 60 sets of testing experiments are carried out, and the corrosion rate is calculated according to the JB/T7901-2001 standard

\subsubsection{Test of Coating Mechanical Properties}

According to Sj 1278-1977 and SJ 1277-1977 to winding experiments are performed on the materials after various surface anti-corrosion treatments to verify the mechanical properties of the coating.

\subsubsection{Economic analysis}

Analyzing the price of materials required for the "fixed parts" part of the main downhole injection tools, comprehensively consider the production and processing costs, and selecting the best surface treatment technology.

Results \& Discussion

\section{Discussion and analysis of experimental results}

\subsection{Optimization of Anti-corrosion and Anti-scaling Test Results for "Moving Body"}

\subsubsection{Anti-corrosion and Anti-scaling Test Results (Figure 1 to Figure 5)}




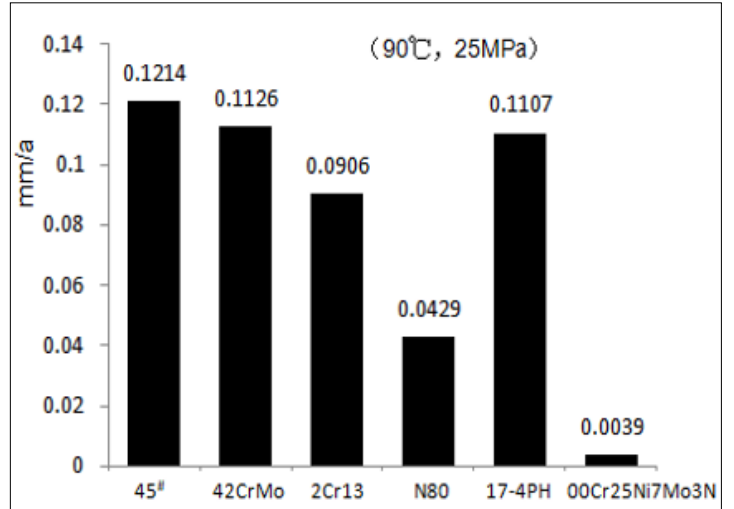

Fig 1. Corrosion Rate of Materials without Corrosive Gas under Low Temperature Condition

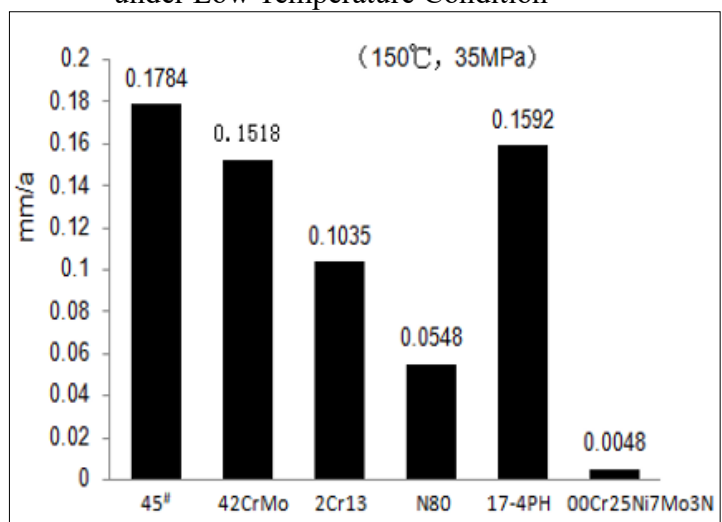

Fig 2. Corrosion Rate of Materials without Corrosive Gas under High Temperature Condition

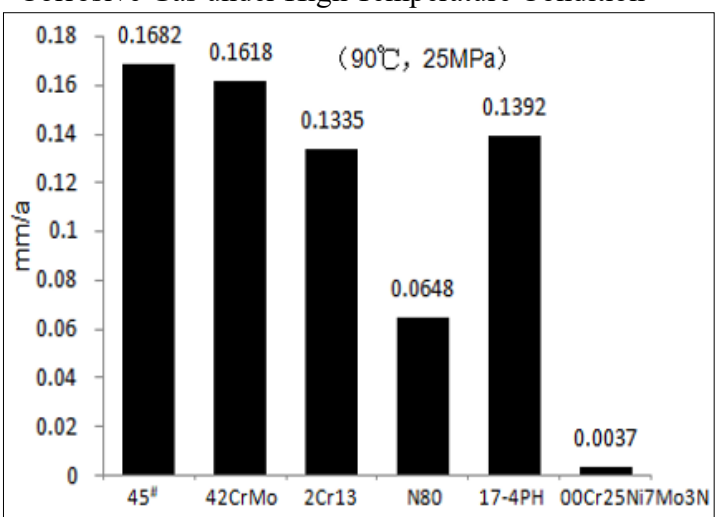

Fig 3. Corrosion Rate of Materials with Corrosive Gas under Low Temperature Condition

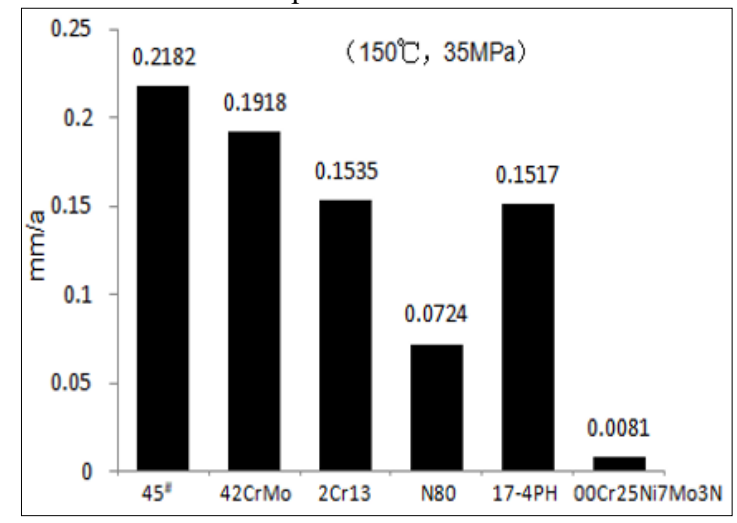

Fig 4. Corrosion Rate of Materials with Corrosive Gas under High Temperature Condition

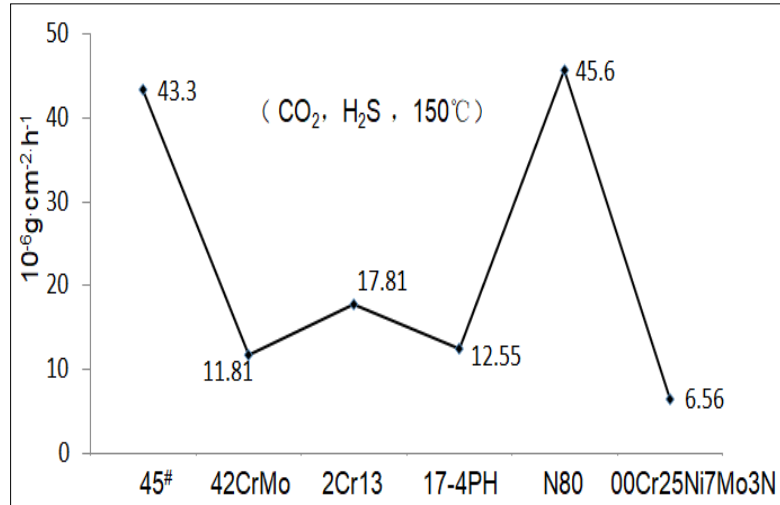

Fig 5. Scaling situation of various materials containing corrosive gas under high temperature conditions

\subsubsection{Query Results of Mechanical Properties of "Moving Body" Components (Table1)}

Table 1 Mechanical properties of 6 different materials

\begin{tabular}{|c|c|c|c|}
\hline Material & $\begin{array}{c}\text { Yield } \\
\text { Strength } \sigma_{\mathrm{s}}\end{array}$ & $\begin{array}{c}\text { Tensile } \\
\text { Strength } \sigma_{\mathrm{b}}\end{array}$ & Elongation \\
\hline 45 & 435 & 600 & 18 \\
\hline $42 \mathrm{CrMo}$ & 550 & 750 & 20 \\
\hline $2 \mathrm{Cr} 13$ & 603 & 655 & 16 \\
\hline $\mathrm{N} 80$ & 600 & 680 & 13 \\
\hline $17-4 \mathrm{PH}$ & 1200 & 1375 & 10 \\
\hline $00 \mathrm{Cr} 25 \mathrm{Ni7Mo3N}$ & 550 & 800 & 25 \\
\hline
\end{tabular}

\subsubsection{Economic analysis results}

After comparing the anti-corrosion and anti-scaling performance and mechanical properties, the current best choice is $00 \mathrm{Cr} 25 \mathrm{Ni} 7 \mathrm{Mo} 3 \mathrm{~N}$ dual-phase steel. According to economic analysis, the price of this material is 45,000 yuan/ton, and the proportion of "movable parts" in the overall tool is $15 \sim 27 \%$, in line with the scope of tool price control.

\subsection{Optimization of Anti-corrosion and Anti-scaling Test Results for "Fixed Parts"}

3.2.1.Anti-corrosion and Anti-scaling Test Results (Figure 6 to Figure 7) 


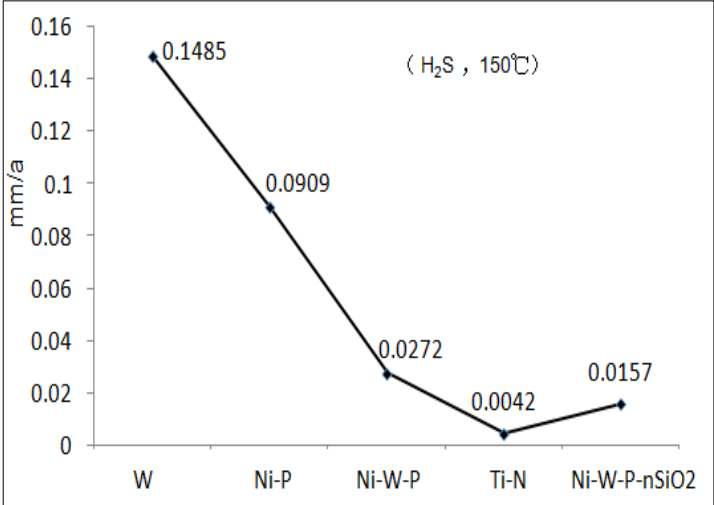

Fig 6. Corrosion Condition of Various Coatings under Corrosive Gas and High Temperature Condition

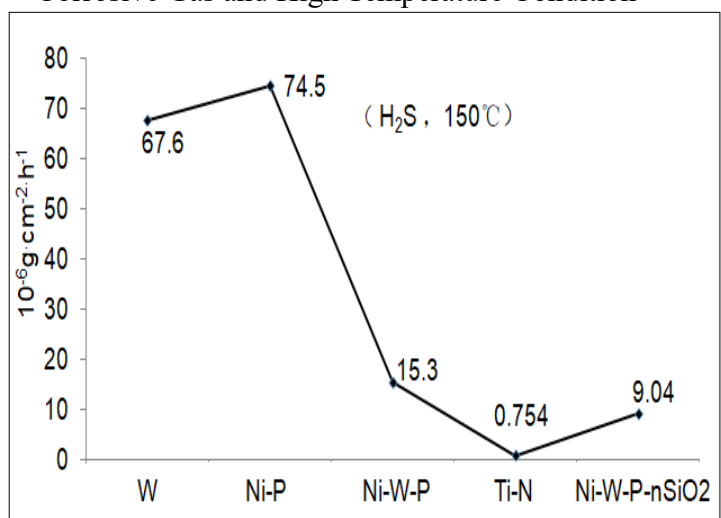

Fig 7. Scaling Condition of Various Coatings under Corrosive Gas and High Temperature Condition

\subsubsection{Mechanical Performance Test Results (Table 2)}

Table 2 Five Kinds of Surface Treatment Technology Mechanical Performance Test Results Records

\begin{tabular}{|c|c|}
\hline $\begin{array}{c}\text { Surface Treatment } \\
\text { Technology }\end{array}$ & $\begin{array}{c}\text { Winding Detection } \\
\text { (Weighting) }\end{array}$ \\
\hline $\mathrm{W}$ & Coating Peeling Off $27 \%$ \\
\hline Ni-P & Coating Peeling Off 19\% \\
\hline Ni-W-P & Coating Peeling Off 9\% \\
\hline Ti-N & Coating Peeling Off 3\% \\
\hline Ni-W-P-nSiO 2 & Coating Peeling Off 7\% \\
\hline
\end{tabular}

\subsubsection{Economic Analysis Results (Table 3)}

Table 3. Five Kinds of Surface Treatment Technology and

\begin{tabular}{|c|c|c|c|}
\hline $\begin{array}{c}\text { Surface } \\
\text { Treatment } \\
\text { Technology }\end{array}$ & $\begin{array}{c}\text { Coating } \\
\text { Thickness }(\mathrm{mm})\end{array}$ & $\begin{array}{c}\text { Coating } \\
\left.\text { Price } ¥ / \mathrm{m}^{2}\right)\end{array}$ & $\begin{array}{c}\text { Valid } \\
\text { Period } \\
(\mathrm{a})\end{array}$ \\
\hline Ni-W-P & 0.06 & 1800 & 4 \\
\hline Ni-P & 0.06 & 800 & 1.3 \\
\hline Ti-N & 0.006 & 3600 & 1.4 \\
\hline W & 0.06 & 300 & 0.6 \\
\hline Ni-W-P-nSiO & 0.06 & 2100 & 4 \\
\hline
\end{tabular}

Experimental results illustrate that Ti-N,Ni-W-P-nSiO2 and Ni-W-P all have strong anti-corrosion and antiscaling performance and better mechanical properties.

\section{Conclusions}

1.The "moving body" of the downhole injection tools is $00 \mathrm{Cr} 25 \mathrm{Ni} 7 \mathrm{Mo} 3 \mathrm{~N}$ duplex stainless-steel, which has excellent corrosion and scale inhibition performance and mechanical properties.

2.Under the control of production coast and validity period, the "fixed parts" of downhole injection tools should adopt $\mathrm{Ni}-\mathrm{W}-\mathrm{P}$ coating or Ni-W-P-nSiO${ }_{2}$ coating.

\section{References}

1. Sun Tao.Research and application analysis of anti-corrosion and anti-scaling technology for downhole tools in oil field [J].Enterprise Technology Practice,2019, 5 (12)

2. Zhang Haiyan, Qu Jingxue, Hao Jingyu. Research and application of anti-corrosion technology for high $\mathrm{CO}_{2}$ gas wells in Jilin Oilfield [J].Journal of Oil and Gas.2012，34 (3)

3. Ji Yanjuan, Zou Junsong, Xu Zhigang, Zhang Feng,Research on the application of new Nano-coatings as internal anti-coatings for the injection wells of water injection wells [J]. Petrochemical applications, 2014, (9): 103-104

4. Gao Yuxin, Fan Jingwu, Dang Guoyi. Prefabrication technology of fusion bonded epoxy powder internal anticorrosion pipeline[J]. Petroleum Engineering Construction.1997, (2): 34-35

5. Wang Hui, Liu Ke,Analysis of $\mathrm{H}_{2} \mathrm{~S}$ Corrosion and Protection of Downhole Tools[J].Chemical Management,2014, (33): 134-136.

6. Xu Zhenyu, Jiang Shihang, Liu Yangda, Chu Rao, Study on the corrosion resistance of electroless Ni-W-P alloy coating [J] .Science and Technology Innovation Review,2014， (14): 26-29 